Session 3260

\title{
SUMMER ENGINEERING PROGRAM IN LONDON
}

\author{
John W. Lucey \\ Dept. of Aerospace and Mechanical Engineering, University of Notre Dame
}

\begin{abstract}
The University of Notre Dame offers a six-week summer program for its undergraduate engineering students in London, England. Students enroll in two technical elective courses for a total of six semester credit hours. The Program includes several required trips to significant technological facilities. Students not only gain academic credit but also the invaluable experience of living for a significant period of time in a culture different than their own. That cultural exposure may well have a greater long-term benefit to students' professional futures than the explicitly technical instruction they receive.
\end{abstract}

\section{Introduction}

Notre Dame's College of Engineering has offered a summer program in London, England since 1988. The objective is to offer the undergraduate engineering student an enriching educational experience in a foreign study environment.

Students live and travel in a foreign culture while enrolled in two engineering courses, obtaining academic credit applicable to their degree requirements. The program is an intensive six -week session based in London, England. Each course meets for the same number of contact hours as an on-campus summer session course for the same number of credit hours. In addition a number of required field trips, one overnight, are integrated into the courses. Generally students have been Notre Dame undergraduate engineering students in good standing, with an occasional student from another institution. Participation in the program allows engineering students to make progress to their intended degree while maturing as well educated members of contemporary society.

Required field trips have varied from year to year. Students have visited engineering projects unique to the United Kingdom, including the Channel Tunnel excavation, the Sellafield nuclear fuel reprocessing plant operated by British Nuclear Fuels, and the Thames Flood Barrier. We have also visited several industrial facilities, including IBM research and manufacturing facilities in Southern England, Astrium, Inmarsat, Accenture, and Brown and Root, Vickers, to observe and discuss the practice of engineering within the United Kingdom and the evolving European Community. These visits allow students to witness the technical interaction of United States and foreign owned companies, and the operation of United States owned companies in an international environment with local management.

Early each summer the class attends a performance at the Regent's Park Open Air Theater. "A Midsummer Night's Dream," "Twelfth Night," "The Taming of the Shrew, " and "Much Ado About Nothing" have, over the years, introduced students to available theater in London.

Program evaluations, based on independent student exit interviews with either the Director of the University's London Undergraduate or London Law Program, have been conducted each year of the program. The evaluator prepares a detailed report of his interviews and conclusions. Over the years the Reports have been uniformly favorable.

\section{Rationale}

Proceedings of the 2002 American Society for Engineering Education Annual Conference \& Exposition Copyright $\odot$ 2002, American Society for Engineering Education 
The University and its officers have long considered foreign study opportunities a valuable aspect of a student's educational program. Prior to 1988 all Colleges of the University but Engineering provided a foreign study option for their students. Notre Dame has had success in conducting foreign study programs for its other Colleges in England, Ireland, France, Austria, Italy, Mexico, Chili, Japan, China, and the Middle East. In the 1999-2000 academic year, the most recent year for which statistics are available, 37 percent of Notre Dame students participated in study programs in other countries. This was the second-highest percentage among American research universities, according to a recent Institute of International Education report.

Typical of United States universities, Notre Dame does not require a foreign language of its engineering students, thereby restricting engineering study abroad for most students to English speaking countries. Hence the choice of London, where the University already has an educational facility. (Recently an academic year program for engineers has begun in Australia.)

The program recognizes a need to make engineering education more responsive to global technological progress and social concerns. Students in the program are exposed both to the unique technological achievements in the United Kingdom, and to the everyday life of the UK and other European countries.

Today's engineering graduates increasingly practice their profession in an international environment. A 1987 National Academy of Engineering Report developed a strong case for a new level of international cooperation on technological issues and reported a growing need for US engineers to respond to the increasing quantity and quality of engineering activity abroad. In its recommendations the report called for making engineering education more responsive to worldwide progress and concerns.

The United Kingdom, birthplace of the industrial revolution and a leading force in the European Economic Community, is a logical choice for the location of our engineering program. London, one of the world's great cities, has a long and interesting history. The development and construction of London's public projects is a significant chapter in the history of technology. Thames River development projects, the Underground transportation network, bridges and the mammoth Thames Flood Barrier (often cited as the eighth wonder of the world) are historic milestones. It is an exciting home for the program.

Economic changes in the European Community including the introduction of a common currency and the removal of trade barriers will affect industrial economies around the world. In their visits to industrial facilities, and from the daily press and television news, students acquire a unique perspective on this transition, which will have such a profound effect on their professional lives. Students based in London observe different national approaches to problems of the environment, economic competitiveness, and labor relations to mention but a few areas which will effect their professional futures.

\section{Location}

The program is based at the existing Notre Dame Centre just off Trafalgar Square. One classroom and two faculty offices are used. The existing Centre staff is utilized. During the summer the facility is shared with Notre Dame's Summer Law Program and a small Architecture program. The Notre D ame Centre is fully utilized during the academic year by a Masters of Law program, an MBA program and the Undergraduate program, which has included Engineering students since 1995.

Students are housed in flats in the Bayswater (W2) area of London, adjacent to Kensington Gardens and some 2 1/2 miles from the classroom building. Some students elect to walk, most use the buses or trains of London Transport. Four or five students occupy each flat. Each flat has two bedrooms, kitchenette, living/dini ng area and private bath. Each is furnished with cooking utensils, incoming telephone and color television. The flats are managed and maintained by Vienna Hotels who provide a weekly cleaning and change of bed linen.

\section{Administration}

Two tenured professors jointly administer the program, with offices in the Notre Dame Centre. The Centre's existing administrative/secretarial staff provides programmatic support. Two Resident Assistants, chosen because 
of their previous experience and familiarity with London, complete the Program's staff. Their background is beneficial to the program, as they are able to advise students on travel plans and everyday London life. They are responsible for maintaining order in the flats and interfacing with custodial and maintenance personnel of the Vienna Hotels Group which manages the flats.

The two Resident Assistants live in the flats with the other students and are responsible for student behavior in the building. Faculty reside in flats in the classroom building.

\section{Student Selection and Orientation}

During the summer prior to a student's enrollment in the program a letter is sent to undergraduate engineers at their home addresses describing the program. An information session for interested students is held in early October. Applications for participation are due before the Thank sgiving holiday. All applications are reviewed for potential disciplinary problems with the Office of the Vice President for Residence Life. Students in recent years have been roughly equally split between those completing their sophomore and junior years.

On campus orientation meetings with the students and the Residence Assistants are held in the spring to answer questions regarding scheduling, appropriate clothing and conditions in London. Another orientation session is held on the students' first day in London.

\section{Academic Program}

Two three credit hour courses are offered. Engineering Economy has been offered each year since the program's inception. It is modified slightly from the course taught on campus to include examples of British engineer ing projects. The second course offered is "Engineering and Technology in a Global Economy" which covers professional ethics and practice and incorporates examples of British practice from projects visited on field trips. Classes meet for two hours each, four days a week, with one of the four days used for a required field trip. The two courses offered are acceptable technical electives in all engineering disciplines.

Two long (Friday through Monday) weekends allow time for individual student travel within England or elsewhere in Europe. It should come as no surprise that students whose nickname is "The Fighting Irish" generally spend one of the weekends in Ireland.

\section{Events}

We hire a coach to meet the students' flights at Heathrow Airport to transport them and their luggage to the flats. After a few hours settle-in time, a lunch is served for the class at a nearby hotel. After the lunch an orientation meeting is held to outline the program and ground rules, provide information on London, and an swer any immediate questions. On the next day, the first day of class, the class takes a narrated bus tour to become familiar with the city.

The first Friday the group travels by boat from Westminster Pier to the Thames Flood Barrier, a major engineering project designed to protect London from flood. The trip includes extensive commentary on the history of the river and those who lived and worked along it. The Visitor's Center at the Flood Barrier contains an operating model of the Barrier and a film show on the need for the Barrier. The class then travels up river to Greenwich to visit the Royal Observatory and Royal Naval Museum.

An overnight trip the third week visits Ironbridge Gorge and British Nuclear Fuel's Sellafield facility. Ironbridge Gorge contains a number of sites associated with the birth of the industrial revolution, including the remains of the first coke fired iron smelter, a Museum of Iron, the world's first bridge constructed of iron, and an Open Air Museum which recreates village life at the start of the Industrial Revolution. From Ironbridge we travel to Lancaster University to spend the night.

The following morning we travel by coach through the edge of the Lake District to the Sellafield plant on the Cumbrian Coast. Sellafield has been reprocessing spent nuclear fuel since 1952 and is the location of the Calder 
Hall nuclear power station, the world's first commercial scale nuclear power generating station, commissioned in 1956. BNFL graciously provides us with an all day guided tour. Sites visited within the Selafield complex, which vary from year to year, have included the Calder Hall reactors, the MAGNOX spent fuel storage and decladding operation, where we observe the sophisticated remote handling equipment used in the process, the Thermal Oxide Reprocessing Plant (THORP), and the Cladding Encapsulation Plant.

A half-day visit to Astrium, a satellite manufacturing and testing facility, has been followed by a visit to the Inmarsat Satellite control facility in London.

We have visited the IBM facilities at Havant and Hursley, both near Portsmouth. At Havant we have been able to observe several advanced manufacturing procedures, while at Hursley we have seen the design and development process in progress. At both sites we heard from upper level managers and young engineers about the challenges and accomplishments working as British nationals in an international corporation.

A visit to the offices of Brown \& Root, Vickers, a firm responsible for the design of off-shore oil drilling platforms, included a series of presentations on past and present engineering projects, their corporate structure, Computer Aided Design techniques and other aspects of the design and development process. Students had an opportunity to experiment with their CAD system.

We visited the Channel Tunnel project, the largest construction project in Europe at that time. In the early years of the program we toured the construction site, but in following years our visit was restricted to the Visitor's Centre, as the construction site became an international frontier. All three tunnels in the project are now open from England to France. The Channel Tunnel Visitor's Center had infor mation about previous attempts to tunnel under the English Channel, dating back to Napoleon's time, a display of work in progress and a model of the completed project, model trains and all.

In previous years we have also visited, or been visited by, AT\&T, Ford Motor Company, Rolls Royce Engines, Olympia \& York, and the Canary Wharf development project.

As a supplement to the program's technical content, members of the class take advantage of the London theater scene, attending an open air performance of a Shakespeare play as a group and attending many of the West End productions on their own. Many also manage to attend the Wimbledon Tennis Championships, athletics (track \& field) competitions, football (soccer) and rugby matches. Despite our best efforts we have yet to stimulate a deep interest in cricket, despite the International Test Matches which are a highlight of any English summer.

\section{Conclusion}

The student fee, which covers round trip air travel, housing (but not meals) and program costs including field trips, has allowed the program to break even for the fifteen years of its existence. Individual travel and food costs add to students' expenses. In addition students give up the opportunity for meaningful summer employment and associated income. This does limit the number of students who are able to participate. Financial aid specifically for the program allows economically pressed students, including minority students, to participate. The fee is incremented annually to accommodate continuing inflation and changes in currency exchange rates.

Our judgement, based on our talks with students during the summer and on campus after our return, on evaluations conducted in London by an independent reviewer, and a limited survey of former participants, is that the program is a huge success. We have had no significant attendance or health problems. Discipline problems have been relatively minor.

The summer engineering program in London is now a well -established offering of Notre Dame's College of Engineering. We expect enrollments to continue in the mid twenties for the foreseeable future.

Proceedings of the 2002 American Society for Engineering Education Annual Conference \& Exposition Copyright $\odot$ 2002, American Society for Engineering Education 
JOHN LUCEY is an Associate Professor of Aerospace and Mechanical Engineering at the University of Notre Dame, Notre Dame, Indiana. He holds a BS in Chemical Engineering from Notre Dame, and an SM and PhD in Nuclear Engineering from the Massachusetts Institute of Technology. He has directed the Notre Dame Summer Engineering Program in London since its inception in 1988. 